International Journal of Social Science and Economic Research

ISSN: 2455-8834

Volume: 05, Issue: 06 "June 2020"

\title{
REVIEWING THE ROLE OF PLAY THERAPY IN THE BEHAVIOURAL MANAGEMENT OF CHILDREN WITH ASD
}

\author{
Armaan Dube \\ American Embassy School, New Delhi \\ DOI: 10.46609/IJSSER.2020.v05i06.021 URL: https://doi.org/10.46609/IJSSER.2020.v05i06.021
}

\begin{abstract}
Through a combination of secondary research including prior scholarly literature, recent reports and news reportage, this paper hopes to critically review studies on the role of play therapy in the behavioral management of children with autism-spectrum disorders, understanding the efficacy of multiple tools used in specific light of varying cultural context. Considering examples in the Indian subcontinent, the study hopes to identify specific forms of play therapy that yield greater results, and critiques the methods by which such results are assessed in the first place. It reviews literature on children on the autism-spectrum and considers alternative and inclusive approaches to non-discriminatory perspectives on autism that considered it a method of learning diversity as opposed to a disability. In this respect, this study analyzes the effectiveness of Preschool Autism Communication Therapy (PACT), which has shown promising results in the adaptation of common play therapy methods to suit the South Asian context and accommodate low income settings.
\end{abstract}

Keywords: Play therapy, Behavioral management, Autism-spectrum, Indian subcontinent

\section{INTRODUCTION}

Autism is one of the world's fastest growing developmental health challenges, with up to 70 million people affected, causing a severe effect on the social development of children (PTI, 2015). There has been an encouraging increase in awareness regarding Autism Spectrum Disorder, or ASD, in both children, adolescents and adults. In general, relatively little has been written on autism in developing countries as compared with what has been published on autism in North America and Europe (Barua and Daley, n.d). From the late 1980s through today, autism related research, treatment and therapy in India has experienced an intense period of activity relative to the previous decades (Barua and Daley, n.d). Growth has occurred in numerous domains: diagnosis, treatment and educational options, parental involvement, involvement of 


\section{International Journal of Social Science and Economic Research}

ISSN: $2455-8834$

Volume: 05, Issue: 06 "June 2020"

civil society organisations, vocational options, human resource development, and legislation (Barua and Daley, n.d).

While such awareness is a step in the right direction, it is also important to analyze whether the methods of treatment and inclusiveness of policy has improved in a substantial manner alongside the same. In order to do so, researchers must take into account income levels, socio economic contexts, and cultural contexts in order to adapt treatment methods to most benefit children in varying situations. Play therapy is one such method that has gained popularity in the past decades, across the world as a way to manage the behaviour of children with ASD (Grant, 2020). Research has determined that play therapy is particularly helpful with respect to remedying communication deficits, such as responding inappropriately in conversation, or difficulty building friendships (Grant, 2020). Several play therapy approaches have shown success in treating children with ASD, most notably filial therapy, Theraplay®, child-centered play therapy, and AutPlay®Therapy (Grant, 2020).

While play therapy has been adopted in schools even in India and developing countries, it is important to note that discrimination continues to exist in the school setting. Ironically, increased awareness of autism among special educators has led, in some cases, to a new type of discrimination (Barua and Daley, n.d). Some schools will turn away children diagnosed as autistic because they feel they cannot provide adequate one-to-one attention, which they have been told a child with autism must have (Barua and Daley, n.d). Further, in countries such as India, pharmacological treatment continues to dominate the ASD related discourse and diagnostic methods, the positive effects of which are often wrongly attributed and the negative effects of which are under reported (Barua and Daley, n.d).

This paper will shed light on play therapy as a form of behavioural management of ASD in children, and critically evaluate the metrics and analytical tools upon which success or failure of play therapy is assessed. From a broader perspective, the paper will also examine the discourse surrounding ASD and the fundamental presumptions that treatment metrics are based upon, aiming to foster a more inclusive approach rather than a stigmatization of ASD as a disability.

\section{BACKGROUND}

Similar to the western world, there has been an increase in the prevalence of autism in India over the years (Juneja and Sairam, 2018). Once considered rare, the current understanding is that autism is in fact one of the more common developmental disabilities (Juneja and Sairam, 2018). The increase in prevalence can be attributed mainly to increased awareness amongst professionals. Changes in case definition, earlier detection, and diagnostic substitution of cases may also be contributory (Juneja and Sairam, 2018). It is crucial to note that symptom expression 


\section{International Journal of Social Science and Economic Research}

ISSN: $2455-8834$

Volume: 05, Issue: 06 "June 2020"

and initial diagnosis that leads to early intervention for children is also heavily influenced by socio economic and cultural contexts.

For example, in the Indian context too, cultural diversity in urban and rural areas. This has effects on developing methods for play therapy. While enquiring about and assessing play, it is seen that many children from lower socioeconomic background don't have access to conventional toys, and are often seen to play with sand, mud, bricks and household utensils (Juneja and Sairam, 2018). These children, especially girls, are also burdened with household responsibilities, and don't have time or the opportunity to play with peers. Many families from lower socio economic strata as well as some with too much emphasis on academics are neither aware of their child's play nor interested in encouraging it (Juneja and Sairam, 2018). In children from higher socio-economic groups, excessive use of smart phones and gadgets may manifest with rote use of westernized English, which may be taken as a positive attribute by the parents (Juneja and Sairam, 2018).

Available standard forms of therapy are mostly ABA-based and include an eclectic mix of playbased interventions, sensory integration, social skills training, special education, speech and language therapy and group therapy (Juneja and Sairam, 2018). However, the therapies are usually not as intensive or clearly defined as recommended in Western literature (Juneja and Sairam, 2018). Research in India has measured the pre and post scores of the dependent variables, viz., communication, socialization, cognition, and problem behaviour (Banerjee and Ray, 2013). Results have indicated the fact that all the stages of structured play offered significant gain in cognition, socialization, and communication of the children (Banerjee and Ray, 2013). Thus, it can be concluded that structured play, particularly, the present 'Play Module', can initiate breaking the glass shell of autism (Banerjee and Ray, 2013).

Researchers both in India and globally, are in the initial stages of determining whether play therapy is an effective intervention for children with autism (Hillman, 2018). In order to recommend play therapy as an evidenced based intervention, researchers need to conduct betterdesigned research - more participants, play therapy as a sole intervention, assessing the impact of play therapy on behaviors over time, and stronger experimental designs - that allows a concrete conclusion to confidently state behavior change was caused by play therapy (Hillman, 2018).

In India, there are largely several private sector operations which implement forms of play therapy through collaboration with schools, etc. There are broadly two types of play therapy most commonly implemented - Non-directive play therapy wherein children are encouraged to resolve their own problems and work toward their own solutions through free play with limited instruction and supervision being given to the child (Caring Minds, n.d). Directive play therapy 


\section{International Journal of Social Science and Economic Research}

ISSN: $2455-8834$

Volume: 05, Issue: 06 "June 2020"

ensures that games are generally chosen for the child, and children are given themes and character profiles when engaging in doll or puppet activities (Caring Minds, n.d). This therapy still leaves room for free expression by the child, but it is more structured than non-directive play therapy (Caring Minds, n.d).

There is a crucial and immediate need for more state sponsored or publically funded services for play therapy, to cater to a much wider range of children, across socio economic conditions and cultural backgrounds, as private services may only be available to elite sets of parents with the ability to comprehend the benefits of play therapy. In lower income and more conservative settings in India, pharmacological intervention remains the norm - these could include methods such as acupuncture, acupressure, Auditory Integrated Therapy, ayurvedic medicine, behavior therapy, magneto therapy, Dimethylglycine facilitated communication, etc (Barua and Daley, n.d). 'Expertise' of astrologers, faith healers, Fakirs, family counseling, family guru, and such others are also sought (Barua and Daley, n.d). Given that these methods are not based on any scientific evidence or proof of improvement of ASD in children, these should be banned by the government through public awareness programs. The following section will elaborate upon the benefits of various tools used to assess the effectiveness of play therapy, with further examples in the Indian context.

\section{DISCUSSION}

Studies and literature reviews conducted on the effectiveness of play therapy have largely been in the western, international context than the South Asian context. A common critique of the available literature on play therapy for behavioural management is that the method of research are most commonly case study designs, which are not conducted on a large scale (Hillman, 2018; Hossain et al, 2017). Therefore, cultural context or empirically verifiable results are difficult to discern from the existing body of research (Hillman, 2018; Hossain et al, 2017). Since case studies are not a strong experimental design it is difficult to generalize results to the larger community (Hillman, 2018). In addition, it is not known whether the change in the participant's behavior was due to the intervention - in this case play therapy - or other extraneous variables since the intervention was not implemented with additional participants (Hillman, 2018).

However, what can be reasonably concluded is that the theory behind play therapy makes it suitable in addressing some of the core difficulties exhibited by children with ASD such as limited social interactions and communication difficulties (Hillman, 2018; Grant, 2020). With play therapy, children have the opportunity to develop trust with the therapist and feel comfortable. Once a child feels safe, he or she may be motivated to engage socially with the play therapist, eventually generalizing his or her skills to home and school environments (Hillman, 2018; Grant, 2020). Another large benefit of play therapy is that parents can be included in play 


\section{International Journal of Social Science and Economic Research}

ISSN: $2455-8834$

Volume: 05, Issue: 06 "June 2020"

therapy sessions and over time take on more of the therapist duties or conduct play therapy sessions at home (Hillman, 2018; Divan, 2017). Hence, play therapy may be a cost effective intervention while also helping parents build stronger relationship with their children (Hillman, 2018).

Due to the cost effectiveness of parent centered play therapy, it has found promising results in the context of South Asian countries which are firstly lower income environments, and secondly, are cultures centered around the family structure and parental involvement more so than western cultures. In this respect, the Preschool Autism Communication Therapy (PACT) has been a radical approach for developing countries such as India, because it involves training nonspecialists to support and guide parents, allowing children and families with few resources to receive the care they need and deserve (Divan, 2017). This is also one of the first initiatives in the world that aims for a more culturally nuanced therapeutic method which incorporates elements of play therapy (Divan, 2017).

Clinical researchers from the Universities of Liverpool and Manchester in UK collaborated with colleagues in south Asia to adapt the therapy (Divan, 2017; PTI, 2015). Successfully tested in India and Pakistan, the partnership aims to improve treatment for an estimated five million children in the region with the disorder (PTI, 2015). Studies attempting to implement the PACT system in low income and South Asian settings found that the PACT intervention is acceptable and relevant to the needs of the local communities and its relatively low intensity makes it is easily transferable (Divan et al, 2015). The method of delivery by non-specialist health workers was also found to be feasible and acceptable (Divan et al, 2015).

In essence, the adapted intervention is based on the same theoretical construct as PACT and utilises a naturalistic approach to scaffolding and developing communication skills in the child with ASD (Divan et al, 2015). The findings accounted for adaptation in some aspects of its content and delivery to enhance contextual acceptability and to enable the intervention to be delivered by non-specialists (Divan et al, 2015; Divan, 2017).

In the cultural context of grandparents or nannies being the primary caregivers, flexibility in the adult targeted for the intervention was introduced. Despite concerns of experts about the 'reflective' nature of the intervention, parents were able to adapt to this approach with ease during video-feedback (Divan et al, 2015). The last stage of PACT, involving an in-depth understanding of language development, has been re-designed to be co-delivered by the specialist supervisors (Divan et al, 2015). Contextually, appropriate metaphors and analogies have been included to illustrate the concept of communication and the details of specific strategies. Non-specialists across the sites had no difficulty in establishing therapeutic alliances with families (Divan et al, 2015). The adaptation contains clear guidelines explicitly detailing 


\section{International Journal of Social Science and Economic Research}

ISSN: $2455-8834$

Volume: 05, Issue: 06 "June 2020"

potential concerns (e.g. behavioural problems) that need to be referred to supervisors, to safeguard non-specialists from being consulted on issues beyond the scope of their training (Divan et al, 2015).

Further studies conducted by NGOs found similar positive effects in adapting PACT as a form of play therapy in India. One of the strengths of this therapy is that its strategies are documented in a manual, which can be translated into several languages (Divan, 2017). The manual allows for consistency by providing all the therapists with the same core techniques to train parents (Divan, 2017). The option of providing therapy at home also forestalls the need for families to travel to a treatment center. Finally, the video recordings allow researchers to review the quality of each session (Divan, 2017). These characteristics seem to make the therapy ideal for use in South Asia. One remaining problem faced in implementation, however, is a lack of trained autism therapists in the region and other limitations such as internet connectivity issues, availability of technology, and the vast differences in cultural background even within the same region in India (Divan, 2017). However, the promising results from the randomized, controlled PACT trials contain important lessons for play therapy and for a more intensive, inclusive future for autistic children.

\section{CONCLUSION}

What remains a crucial measure to be taken in the future is more research in varied cultural contexts, to truly implement play therapy in a manner that considers ASD to be a learning diversity rather than a disability. In this sense in South Asia, PACT is a promising road ahead to assist caregivers in developing greater confidence in their knowledge of autism and how it affects their child. More research on the efficacy of child-centered play therapy needs to be conducted. There is a need to extend the conversation on how play can be incorporated into effective interventions for children with ASD (Hillman, 2018). Since play is central to the developmental of all children, and some children with ASD have deficiencies in play, it is important to look at methods of using play in future interventions for children with ASD - either using play therapy as a stand-alone intervention or in conjunction with evidence-based behavioral interventions (Hillman, 2018).

In South Asian countries like India, knowing the extent of ASD as a public health problem is a priority and starting point (Hossain et al, 2017). There is an urgent need for all countries of this region to conduct well-designed epidemiological research using uniform and appropriate tools (Hossain et al, 2017). Knowing the prevalence could help choosing screening and diagnostic tools that are applicable, culturally acceptable, and cost-effective to identify individuals who can benefit the most from early diagnosis and intervention (Hossain et al, 2017). 


\section{International Journal of Social Science and Economic Research}

ISSN: $2455-8834$

Volume: 05, Issue: 06 "June 2020"

The end-goal for therapeutic methods relating to ASD in children must be educational justice and a change in societal attitudes (Merry, 2019; Barua and Daley, n.d). PACT is useful in this respect, especially in India, where parents are not expected to have an opinion in the kind of interventions that the child is put on (Barua and Daley, n.d). By involving parents and family members in the treatment, a more positive familial environment is created, thus improving the status of the child as a child whose needs must be accommodated for, rather to be seen as a liability to the family. Giving parents skills that allow them to generalize strategies across multiple areas of the child's life (Divan, 2017). It is an alternative and more inclusive approach to equip children with the skills they need to be as independent as possible, and function effectively in their environment to the greatest extent possible (Merry, 2019). Such an approach will ensure that not only is there protection and care of children with autism, but also an increase in the child's active participation and independent functioning in their environment (Merry, 2019).

\section{REFERENCES}

Banerjee, M and Ray, SG, (2013), 'Development of play therapy module for children with autism', Journal of the Indian Academy of Applied Psychology, Vol.39, Issue 2

Barua, M, and Daley, T, (n.d), 'Autism', Rehabilitation Council of India, http://www.rehabcouncil.nic.in/writereaddata/autism.pdf

Caring Minds, (n.d), 'Play Therapy', https://caringminds.co.in/children-play-therapy/

Divan, G, (9 May 2017), 'Novel autism treatment translates well to South Asian nations', Spectrum, https://www.spectrumnews.org/opinion/viewpoint/novel-autism-treatmenttranslates-well-south-asian-nations/

Divan, G, et al, (2015), 'Adapting an evidence-based intervention for autism spectrum disorder for scaling up in resource-constrained settings: the development of the PASS intervention in South Asia', Global Health Action, Vol.8, Issue 10

Grant, R. J. (2020). Play therapy for children with autism spectrum disorder. In H. G. Kaduson, D. Cangelosi, \& C. E. Schaefer (Eds.), Prescriptive play therapy: Tailoring interventions for specific childhood problems (p. 213-230). The Guilford Press.

Hillman, H, (1 January 2018), 'Is Play Therapy an Evidenced-Based Intervention for Children with Autism?', Autism Spectrum News, https://autismspectrumnews.org/is-play-therapyan-evidenced-based-intervention-for-children-with-autism/ 
Hossain, M, et al, (2017), 'Autism Spectrum disorders (ASD) in South Asia: a systematic review’, BMC Psychiatry, Vol.17, Issue 281

Juneja, M, and Sairam, S, (15 March 2018), 'Autism Spectrum Disorder - An Indian Perspective', Recent Advances in Autism, SM Group, http://www.smgebooks.com/autism/chapters/AUT-18-12.pdf

Merry, M, (2019), 'Do Inclusion Policies Deliver Educational Justice for Children with Autism? An Ethical Analysis', Journal of School Choice, Vol 14, Issue 1

PTI, (17 December 2015), 'New autism treatment to help children in India', The Economic Times, https://economictimes.indiatimes.com/news/science/new-autism-treatment-tohelp-children-in-india/articleshow/50218946.cms 